\title{
Development and Progress of Engineering of Skeletal Muscle Tissue
}

\author{
Hua Liao, M.D., ${ }^{1}$ and Guang-Qian Zhou, Ph.D. ${ }^{2,3}$
}

Engineering skeletal muscle tissue remains still a challenge, and numerous studies have indicated that this technique may be of great importance in medicine in the near future. This article reviews some of the recent findings resulting from tissue engineering science related to the contractile behavior and the phenotypes of muscle tissue cells in different three-dimensional environment, and discusses how tissue engineering could be used to create and regenerate skeletal muscle, as well as the extended applications and the related patents concerned with engineered skeletal muscle.

\section{Introduction}

$\mathbf{T}$ ISSUE ENGINEERING REPRESENTS a scientific approach that attempts to mimic neoorganogenesis. ${ }^{1}$ In contrast to the transplantation of donor organs, tissue engineering starts with cultured proliferating cells and aims at reconstituting a tissue-like structure in culture. Regenerating or engineering new tissues may be a potential solution for the replacement of lost, damaged, or failing tissues and organs in general ${ }^{1,2}$; therefore, many investigations have been developed and attempted to regenerate human tissues that have recently entered into clinical practice in the case of tissues such as skin, bone, and cartilage. ${ }^{3-8}$ Further, the creation of skeletal muscle tissue using tissue engineering methods holds promise for the treatment of a variety of muscle diseases, including skeletal myopathies such as muscular dystrophy or spinal muscular atrophy ${ }^{9,10}$; in addition, traumatic injury, aggressive tumor ablation, and prolonged denervation are common clinical situations that often result in significant loss of muscle tissue and require subsequent surgical reconstruction. Engineering skeletal muscle tissue remains still a challenge, and numerous studies have indicated that these techniques may be of great importance in medicine in the near future, while several reviews have summarized those construct techniques and described the development of muscle engineering. ${ }^{11-13}$ In this article, we review some of the recent findings resulting from tissue engineering science related to the contractile behavior and the phenotypes of muscle tissue cells in different three-dimensional (3D) environment and discuss how tissue engineering could be used to create and regenerate skeletal muscle, as well as the extended applications and the related patents with engineered skeletal muscle.

\section{Engineering Skeletal Muscle Tissue}

According to the structure and function of skeletal muscle, the requirements of engineered muscle are as follows: reconstructed muscle is a parallel alignment of myofibrils with myosin/actin filaments, intracellular calcium storage, and acetylcholine receptors, which are needed for creating direct forces and functional use. The neotissue must be biocompatible, must integrate and regenerate lost muscle tissue, and needs to be vascularized and innervated. ${ }^{14}$ Khodabukus et al. ${ }^{11}$ further points out that for engineered muscle to function as an effective model for the study of muscle physiology and function, it needs to satisfy some criteria. First, there needs to be a fast, easy, and standardized technique for engineering muscle. Second, it needs to be possible to engineer the tissue from transformed skeletal muscle cells such as $\mathrm{C} 2 \mathrm{C} 12 \mathrm{~s}$ to decrease the variability of primary cell isolation and to allow for stable mutations to be made for testing gene function. Third, the physiology and function of the tissue need to be readily testable. Fourth, the model needs to be able to reproduce the effects of exercise/developmental stimuli. Fifth, the model needs to use standard, easy-to-use, and relatively inexpensive machines so that neither the cost nor the complexity of the engineering prevents investigators from being able to use the system.

Two general approaches are adopted to engineer artificial skeletal muscle tissue. One way is to regenerate autologous satellite cells by biopsy, expand and differentiate cells in a 3D defined environment in vitro in an artificial bioreactor, and reimplant the neotissue after differentiation has taken place (in vitro tissue engineering). ${ }^{14-16}$ The second approach involves the generation of satellite cells, expansion of cells

\footnotetext{
${ }^{1}$ Department of Anatomy, Southern Medical University, GuangZhou, P.R. China.

${ }^{2}$ Department of Orthopaedics and Traumatology, Hong Kong University, Hong Kong, P.R. China.

${ }^{3}$ Division of Tissue Engineering and Stem Cells, Key State Laboratory of Biotherapy, Sichuan University, Chengdu, P.R. China.
} 
in vitro, and reimplantation of donor cells using a transport matrix, which allows differentiation into myotubes in vivo to occur (myoblast transfer therapy). Implanted myoblasts might serve as vehicles for the delivery of recombinant proteins (in vivo tissue engineering). ${ }^{14-16}$

The first reported 3D engineered skeletal muscle seeded partially differentiated primary avian myoblasts within a collagen gel matrix atop a stainless steel mesh or a flat nylon ring attached to the bottom of the dish. ${ }^{17}$ Unlike twodimensional primary avian myoblast monolayers that detach after 5-6 days in culture, the embedded cells could be maintained for 3-4 weeks as a "floating sheet" of myotubes suspended above the culture dish under constant mechanical tension as a result of their attachment to either the nylon ring or steel mesh (Fig. 1A). As a result of the extended time in culture, the embedded cultures contained higher levels of protein, including myosin heavy chain (MHC), DNA, and a higher ratio of protein-DNA. ${ }^{17}$ Further, the embedded cultures showed the formation of neonatal-like myofibers with characteristics such as a well-developed basal lamina, wellorganized contractile machinery, and peripherally located myonuclei.

Many researchers use the cells-in-gel technique developed simultaneously in the Matsuda and Vandenburgh' laboratories $^{18,19}$ to replace the embedded monolayer technique. In this technique, myoblasts were mixed with an extracellular matrix (ECM) solution (collagen I or Matrigel), and then transferred to a mold and allowed to set. ${ }^{18-20}$ After a few days in culture, the medium was changed to promote the fusion and differentiation of the myoblasts (Fig. 1B). This technique decreased the culture work before the formation of constructs and had the increased flexibility of using molds of any shape. However, when the diameter of the construct was greater than $500 \mu \mathrm{m}$, the core of the muscle became necrotic. ${ }^{18}$ The cellsin-gel technique is very effective for producing a gene delivery system, ${ }^{19}$ but there have been no reports on the ability of these constructs to produce force when electrically stimulated. The specific force (force/tissue cross-sectional area) of cells-ingel constructs is quite low because of the amount of scaffold required and the resulting inhibition of muscle cell fusion. However, the low-specific force makes it difficult to interpret the functional relevance of these tissues.

The novel technique for engineering 3D muscle uses selforganization of a muscle cell monolayer. Strohman and colleagues $^{21}$ in 1990 reported first that primary skeletal muscle cells could form a 3D construct in the absence of an external scaffold. In this report, the authors grew primary myoblasts on a membrane of Saran Wrap held in place using steel pins fixed in a layer of Sylgard (polydime-thylsiloxane). As the muscle cells differentiated, their contractile activity caused the monolayer to detach from the membrane and rolled into a starfish-shaped structure held in tension by cellular adhesion to the stainless steel pins. As the myotubes reorganized into a 3D structure, the normal connective tissue layers, epimysium, perimysium, and endomysium, were produced by the fibroblasts in the culture (Fig. 1C). Like the other models, these muscle constructs expressed more developmentally mature MHCs than observed in monolayers. ${ }^{21}$ The Dennis laboratory used the observations made by Strohman and his colleagues ${ }^{21}$ to develop a repeatable technique for engineering 3D skeletal muscle tissue for the study of the functional development of muscle. ${ }^{22,23}$ In place of the Saran
Wrap, laminin-coated Sylgard plates were used. The laminin promoted cell adhesion and mobility, whereas the Sylgard allowed the attachment of two sutures to the dish. After the myoblasts differentiated and began to contract, they detached from the plate and reorganized into a cylindrical structure using the sutures as tendon-like anchors. ${ }^{22}$ This structure was morphologically similar to skeletal muscle in vivo displaying individual fibers in a loose sarcomeric array. Although the presence of myoblasts was necessary for the development of contractile tissue, fibroblasts and the ECM they produced were essential to the formation of the 3D tissues. The 3D muscle tissue produced in this manner, termed Myooids, contracted spontaneously producing approximately $25 \mu \mathrm{N}$ of force. The Myooids can be generated from a standardized technique from either primary cells or a coculture of $\mathrm{C} 2 \mathrm{C} 12$ and NIH 3T3 cells, and their physiology and function were readily testable. However, Myooids took approximately 35 days to form in culture, and a source of fibroblasts was required for tissue formation. ${ }^{22,23}$

To address these concerns, Huang et al. ${ }^{24,25}$ developed a modified method to engineer self-organized 3D engineered muscles. In place of the fibroblasts and laminin, they used a biodegradable gel of fibrin. Muscle cells were plated on a thin film of fibrin where they proliferated and then fused to form myotubes. As with the Myooids, the cells contracted the gel around two anchors that can be removed from the substrate for testing or mechanical interventions. The primary differences between fibrin constructs and Myooids are that they form in 7-10 days, they can be made in the complete absence of fibroblasts, and they produce twice as much active force as the Myooids. They also performed the generation of engineered muscles from $\mathrm{C} 2 \mathrm{C} 12$ cells. $^{24,25}$ These constructs produced approximately the same amount of force as Myooids and can survive in culture for upward of 3 weeks. Cells can be cultured for a sufficient time to permit the study of long-term changes in muscle phenotype or function.

The composition of the ECM plays an essential role in the attachment, alignment, and differentiation of myoblasts, while the ECM also provides a framework for cell adhesion and tissue growth, which promotes cell proliferation and differentiation. ${ }^{26,27}$ Many researchers put their eyes on special biomaterials with the same internal structures as skeletal muscle matrix, which are biocompatible and bioresorbable, and maybe the replace of ECM of skeletal muscle tissue in vitro. The matrices used in muscle tissue engineering can be divided into synthetic and biologically derived biomaterials, which are cocultured with myoblasts usually in vitro (Fig. 1D). Saxena et al. ${ }^{28}$ placed myoblasts onto polyglycolic acid (PGA) meshes and transplanted them in vivo. After 6 weeks, a vascularized muscle-like tissue could be seen. Some investigators established in vitro cell cultures cultivating muscle cells in Matrigel. However, Matrigel, an extract from the Engelbreth-Holm-Swarm mouse sarcoma, contains various ECM proteins and growth factors in undefined concentrations. It has the ability to change gene expression in cells and promotes differentiation into myoblasts. It has been used in combination with collagen as a 3D scaffold, but because of its origin it is suitable only for experimental models and not for clinical use. ${ }^{29}$

It has been shown that biological materials can support in vivo and in vitro cell adhesion and proliferation. Acellular matrices, which have been remodeled in living tissues and 
can function as bladder, urethra, and small bowel substitutes, $^{30-32}$ are also explored about its possibility of being the biological muscle tissue scaffold. Moreover, in vivo evolution after transplantation of acellular constructs is inspiring, and few skeletal muscle tissue engineering studies have reported on successful generation of living tissue substitutes for func- tional skeletal muscle replacement. There are several potential advantages to using acellular tissue as a scaffold for producing engineered muscle constructs. First, the process to remove cells renders the tissue not only acellular but also nonimmunogenic. Engineered muscle constructs designed for use in vivo must be capable of force production and must also

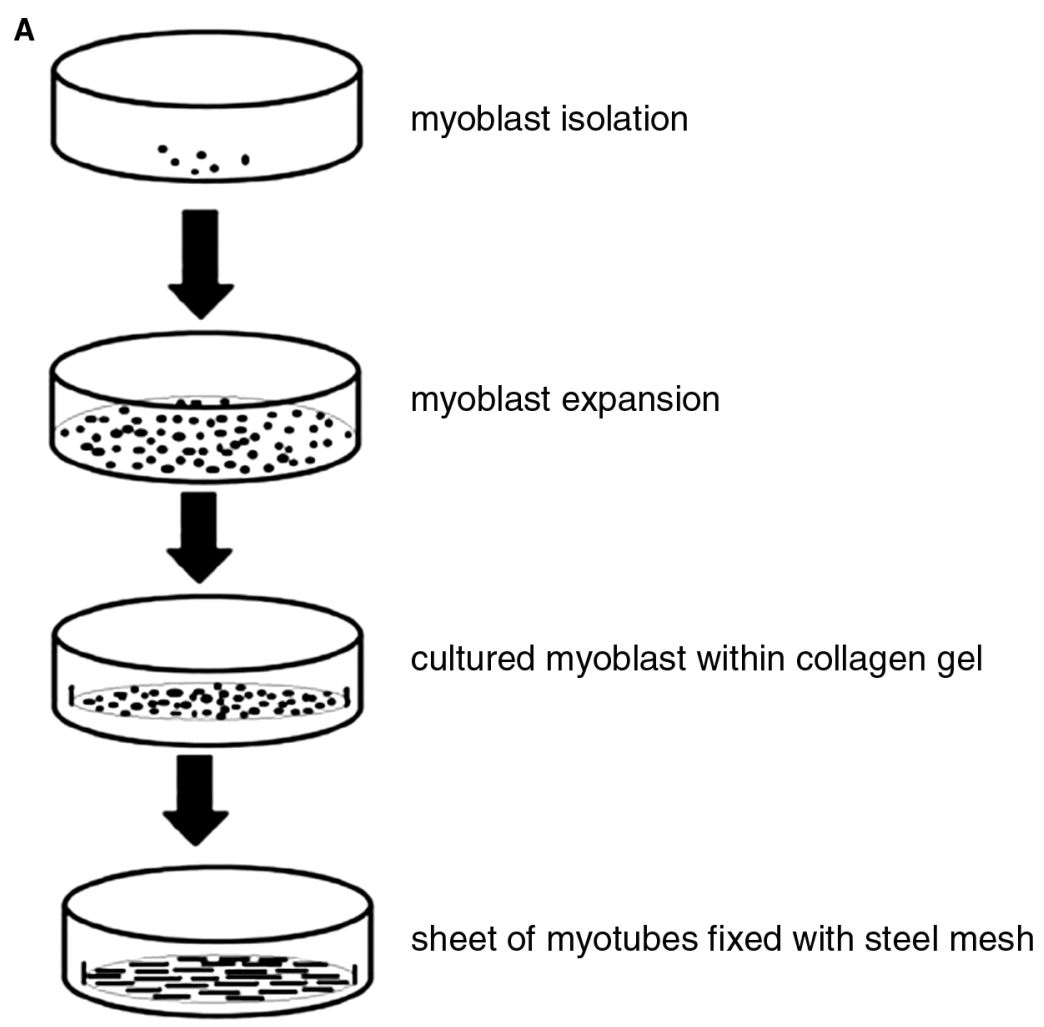

B

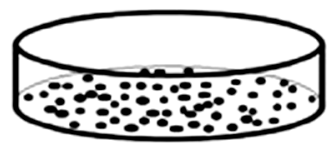

myoblast expansion

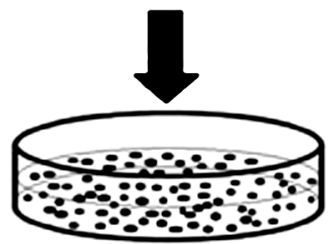

myoblasts are mixed with extracellular matrix

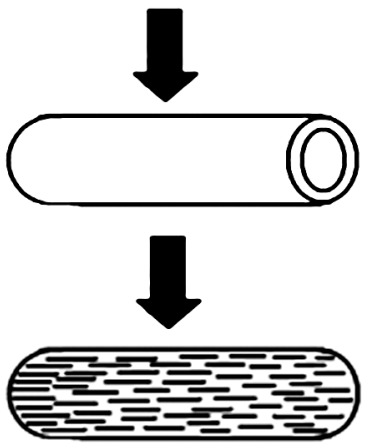

the casted mold

the mixture of cell and matrix are transfered to the mold and allowed to set, followed by myotube formation

FIG. 1. Different methods for engineering skeletal muscle tissue. (A) Floating collagen sheet of myotubes; (B) the casting extracellular matrix involving myotubes; (C) self-organized 3D engineered muscles; (D) cocultured myoblasts with specific biomaterials. 
C
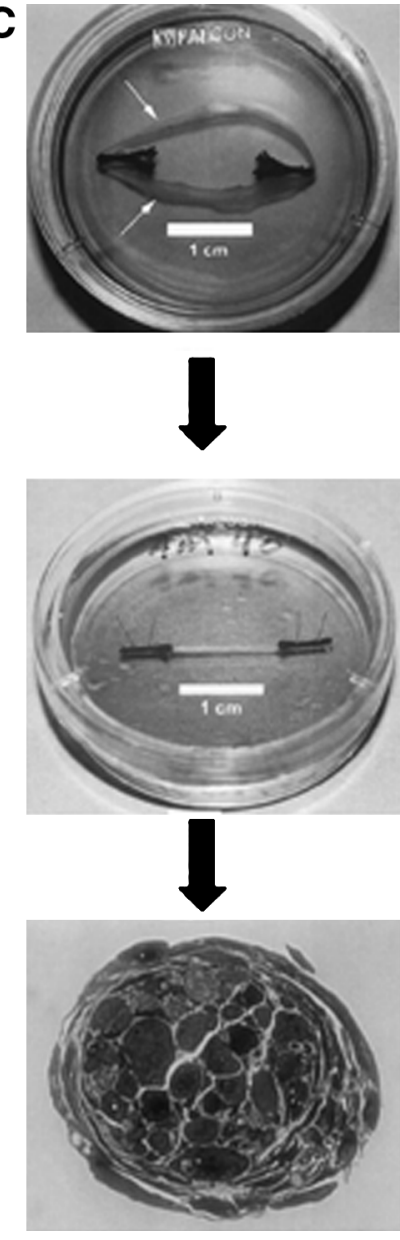

D

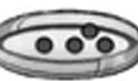
$\checkmark$
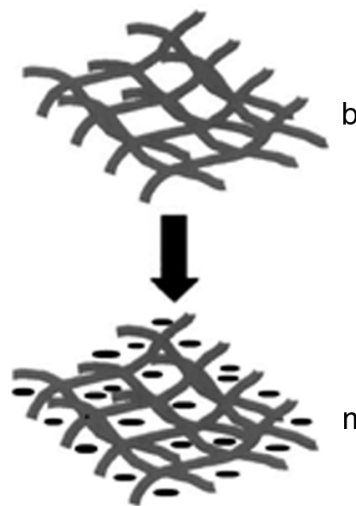

myoblasts are seeded into the matrix

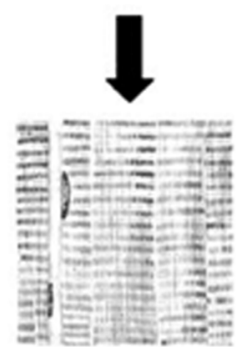

muscle tissue generated in vitro

myoblast are seeded on the top of extracellular matrix to form myotubes and contract the matrix

the $3 \mathrm{D}$ engineered muscles are ready

the section of engineered muscle tissue

myoblast expansion biocompatible muscle matrix

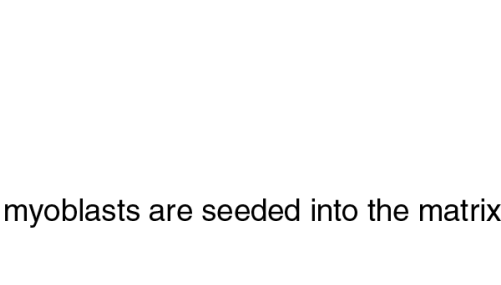

FIG. 1. (Continued) 
be immunologically inert. Second, the remnant neural pathways through the acellularized tissue scaffold may facilitate the incorporation of peripheral nerves into the acellular constructs, promoting innervation. Third, it may be possible to use the remnant ECM from the native vascular system in acellular skeletal muscle to perfuse the constructs, allowing them to grow larger, produce more force, and reestablish a fully recellularized vascular bed. In addition, the use of acellular muscle may allow maintenance of a construct's size and shape after implantation. Further, the retained ECM proteins and residual endomysial tubes may enhance incorporation of such a construct in vivo. ${ }^{33}$ The members of Conconi group ${ }^{34,35}$ cultured myoblasts from rat flexor digitorum brevis, harvested, and seeded on patches of homologous acellular matrix, obtained by detergent-enzymatic treatment of abdominal muscle fragments. Myoblast-seeded patches were transplanted to repair obliqui abdominis muscles, which showed well-preserved muscle structure, abundant blood vessels and myoblasts, and electromyography evidenced in them single motor-unit potentials about 9 days. This cell-matrix constructs were also used to repair a full-thickness defect of abdominal wall of female Lewis rats. The result showed that the implants appeared well preserved, were integrated in the host tissue, and maintained their original dimension and thickness until 9 months, as demonstrated by the expression of SrY mRNA and by the presence of $Y$ chromosome probe signal. ${ }^{35}$ The authors concluded that autologous myoblast-homologous acellular muscle matrix constructs were a promising tool for body-wall defect repair, because they were in vivo repopulated by skeletal muscle fibers and nervous system elements and maintained their structural integrity, following the host development.

Collagens and alginate hydrogels have been used to replace the ECM in vitro, to enhance the attachment of myoblasts, or to alter their growth. ${ }^{27,36,37}$ However, these matrices are not biodegradable, and some are potentially immunogenic. ${ }^{38,39}$ Because in vitro skeletal muscle tissue engineering involves culturing isolated primary myoblasts in an environment leading to the formation of a 3D tissue construct, ideal matrices for such an approach should provide a high surface area for cell-matrix interactions, sufficient space for ECM generation, and a minimal diffusion barrier during in vitro culture. ${ }^{40,41}$ Moreover, the matrix should be resorbable once it has served its purpose of providing a primary structure for the developing tissue. ${ }^{38,42}$ Fibrin possesses the above-mentioned features, and it is an ideal cell culture matrix ${ }^{42,43}$; therefore, Bach et al. ${ }^{44-46}$ developed a 3D fibrin matrix seeded with myoblasts. They focused on myogenic transcription factors, such as MyoD and Myogenin, and the acetylcholine receptor, and proved that the fibrin 3D matrix was the structural basis and the promoter of cell survival, proliferation, and cell organization. Thus, it served not only as a 3D structure for the culture system but offered essential additional biologic properties. Myoblasts can proliferate and fuse to myotubes in the 3D fibrin matrix.

Recently, new polymer biomaterials are followed interest by muscle engineering researchers. Williamson et al. ${ }^{47}$ produced poly( $\varepsilon$-caprolactone) (PCL) fibers by wet spinning from solutions in acetone under low shear (gravity flow) conditions. This gravity spun polycaprolactone fibers were used to construct muscle tissue adopting fibroblasts and myoblasts in cell culture. They obtained engineered muscle using this gravityspun PCL fibers for 3D scaffold production. Masuko et al. ${ }^{48}$ adopted another scaffold, chitosan-peptide complex based on the selective reaction of chitosan with 2-iminothiolane, to engineer skeletal muscle tissue in vitro. Shah et al. ${ }^{49}$ investigated the use of phosphate-based glass fibers as a potential scaffold material for the in vitro engineering of craniofacial skeletal muscle. They used human masseter-derived cell cultures to seed the glass fibers, which were arranged into various configurations. Growth factors and matrix components were used to manipulate the in vitro environment. Outcome was determined with the aid of microscopy, time-lapse footage, immunofluorescence imaging, and CyQUANT proliferation, creatine kinase, and protein assays. They concluded that a $3 \mathrm{D}$ mesh arrangement of the glass fibers was the best at encouraging cell attachment and proliferation. In addition, increasing the density of the seeded cells and using Matrigel and insulin-like growth factor I enhanced the formation of prototypic muscle fibers. Considering that skeletal muscle consists of parallel bundles of myotubes formed by the fusion of myoblasts, Huang et al. ${ }^{50}$ fabricated nanofibrous and micropatterned polymers as cell culture substrates to guide the morphogenesis of muscular tissue. The nanoscale and microscale topographic features regulated cell and cytoskeleton alignment, myotube assembly, myotube striation, and myoblast proliferation. This bottom-up approach from nanoscale to tissue level demonstrated the potential of nanofibrous polymers for engineering the assembly of cell and tissue structure. Riboldi et al. ${ }^{51}$ investigated the suitability, as scaffold for skeletal muscle tissue engineering, of a known biodegradable block copolymer (DegraPols) processed by electrospinning in the novel form of microfibrous membranes. The scaffolds were characterized with reference to their morphological, degradative, and mechanical properties. Subsequently, cell viability, adhesion, and differentiation on coated and uncoated DegraPols slides were investigated using line cells (C2C12 and L6) and primary human satellite cells. The membranes exhibited absence of toxic residuals and satisfactory mechanical properties. A promising cellular response was also found in their preliminary experiments. Positive staining for $\mathrm{MHC}$ expression indicated that differentiation of $\mathrm{C} 2 \mathrm{C} 12-$ multinucleated cells occurred within the porous elastomeric substrate. The author regarded the suitability of electrospun DegraPols membranes as scaffolds for skeletal muscle tissue engineering, which represented a promising alternative to scaffolds currently used in this field.

In 2006, Lam et al. ${ }^{52}$ reported alignment of prefused and differentiated skeletal muscle cells in vitro by use of continuous micropatterned wavy silicone surfaces, with features sized 3, 6, and $12 \mathrm{~mm}$ in periodicity. Wave features with $6 \mathrm{~mm}$ periodicity produced the most healthy, aligned myoblasts. Alignment was found to be a function of plating density. Further growth on these substrates with aligned myoblasts promoted fusion, yielding healthy aligned myotubes. They thought that method will be useful for applications in which differentiated myogenic cells need to be aligned unidirectionally as in the development of engineered muscle. At present, the modified scaffolds were developed and applied extensively in muscle tissue engineering field. For example, Boontheekul and Mooney ${ }^{53}$ took selected controlled degradation alginate scaffold as a delivery vehicle for skeletal muscle tissue engineering; Huber et al. ${ }^{54}$ used electrospun, parallel aligned nylon 6/6 microfiber arrays for the culture of $\mathrm{C} 2 \mathrm{C} 12$ myoblasts and their differentiation to form 
mechanically stable, orientated myotubes in vitro. Yan et al. ${ }^{55}$ adopted a novel technique. They constructed a multilayered culture of skeletal muscle cells, derived from neonatal satellite cells, using polarized matrix of type I collagen fibrils that were distributed in a 3D pattern of organization that mimicked many of the features of intact tissue. These multilayered cultures were composed of elongated multinucleated myotubes that were MyoD positive. Histological studies indicated that the multiple layers of myotubes can be distinguished. Expression of muscle-specific markers such as MHC, Dystrophin, integrin alpha-7, alpha-enolase, and beta-enolase was detected at levels near adult values, while physiological measurements of the engineered skeletal muscle showed that they tetanized and displayed physiologic force length behavior, although developed force per cross-sectional area was below that of native rat skeletal muscle. In 2008, the miniature bioartificial muscles were produced by tissue engineering skeletal muscle myoblasts into 3D muscle with parallel myofibers attached to two flexible microposts, which acting as artificial tendons in a 96-well plate format in the lab of Vandenburg et al. ${ }^{56}$ They adopted Sylgard 184 to cast 7-mm-diameter, 6-mm-deep wells with flexible attachment microposts of varying diameters $(300-800 \mu \mathrm{m}), 4-5 \mathrm{~mm}$ tall, and $4 \mathrm{~mm}$ apart. Miniature bioartificial muscles generated tetanic (active) forces upon electrical stimulation measured with a novel image-based motion detection system. Choi et al. ${ }^{57}$ examined the feasibility of using PCL/collagen-based nanofibers using electrospinning as a scaffold system for implantable engineered muscle. Their aligned composite nanofiber scaffolds seeded with skeletal muscle cells provided implantable functional muscle tissues for patients with large muscle defects. Kroehne et al. ${ }^{58}$ described the application of artificial scaffolds (collagen sponges [CS]) consisting of collagen-I with parallel pores (width $20-50 \mu \mathrm{m}$ ) using the permanent myogenic cell line C2C12. CS were infiltrated with a high-density cell suspension, incubated in medium for proliferation of myoblasts before further culture in fusion medium to induce differentiation and formation of multinucleated myotubes. The biodegradable CS with parallel pores supported the formation of oriented muscle fibers, and formed in situ with host contributions in the outer portions of the regenerates 14-50 days after surgery when the constructs were grafted into the beds of excised anterior tibial muscles of immunodeficient host mice. Propst et al. model system combined a novel aligned collagen tube and autologous skeletal muscle satellite cells to create an engineered tissue repair for a surgically created ventral hernia. They observed the significant persistence of transplanted skeletal muscle cell mass within the engineered repair, the integration of new tissue with adjacent native muscle, and the presence of significant neovascularization. ${ }^{59}$

\section{Loading, Testing, and Applying of the Engineered Muscle Tissues}

There have been several attempts to induce fusion of myoblasts to myotubes in vitro, imitating the in vivo conditions during myogenesis. Mechanical stimulation is one important factor during myogenesis that influences gene expression, protein synthesis, and total RNA/DNA content. ${ }^{60-62}$ The parallel alignment of myotubes can be induced by stretch stimulation. ${ }^{63}$ It has been shown that mechanical forces also have an important impact on mature skeletal muscle on myofiber diameter, cell number, and myofiber composition. Vandenburg and Kaufman ${ }^{64}$ are the first to demonstrate that stretch of muscle cells in vitro could be used to model hypertrophy in vivo. After cyclic stretch, the rate of amino acid uptake, protein synthesis, and the total protein isolated all increased. Baar et al. used a similar model to show that stretch of myotubes in vitro resulted in an increase in the ribosomal S6 protein kinase (S6K1) activity, potentially connecting myotube stretch to the increase in protein synthesis. ${ }^{65}$ Two reports have shown that stretching 3D engineered skeletal muscles also has similar effects to exercise in vivo. ${ }^{20,62}$ Cheema and colleagues ${ }^{20}$ had shown that the stretch of engineered muscles resulted in increased production of mechanogrowth factor similar to resistance exercise. Powell et al. improved the development of 3D human skeletal muscle tissue using collagen and Matrigel as 3D scaffold by mechanical stimulation. ${ }^{62}$ Other studies focusing on the in vitro creation of skeletal muscle showed a different morphologic and functional appearance without mechanical stimulation in comparison to native skeletal muscle. Matsumoto et al. ${ }^{66}$ showed that the simple application of a continuous strain to a fibrin gel facilitated the development of fibril alignment and bundle-like structures in the fibrin gel in the direction of the applied strain. Myoblasts cultured in this gel also exhibited well-aligned cell patterning in a direction parallel to the direction of the strain. Interestingly, the direction of cell proliferation was identical to that of cell alignment. Finally, the oriented cells formed linear groups that were aligned parallel to the direction of the strain and replicated the native skeletal muscle cell patterning. In addition, vein endothelial cells formed a linear, aligned vessellike structure in this system.

Because ECM content was significantly higher, myofiber density was low, and maturation was incomplete without stimulation for engineered muscle, ${ }^{14,67}$ the in vitro regenerated skeletal muscle tissue could achieve only $1 \%$ to $2 \%$ of forces of native skeletal muscle. ${ }^{22,23,67}$ To improve the ratio of muscle fibers and ECM, Powell et al. ${ }^{62}$ created a mechanical cell stimulator that was able to stretch and relax the cell cultures in vitro, involving a force transducer measuring passive forces and viscoelastic properties. The mechanical stimulation improved the structure of the engineered skeletal muscle by increasing the mean myofiber diameter, the elasticity, and the myofiber area percentage. However, the tissue that resulted was not an appropriate substitute for functional implantation, although this neotissue came closer to skeletal muscle than other attempts. Computerized mechanical application of mechanical forces to differentiating skeletal muscle myoblasts in vitro generated $3 \mathrm{D}$ artificial muscle organs. ${ }^{68}$ These organs contained parallel networks of long unbranched myofibers organized into fascicle-like structures. Tendon development was initiated, and the muscles were capable of performing directed, functional work. This kinetically engineered organs provided a new method for studying the growth and development of normal and diseased tissue. ${ }^{68}$ The mechanical and mechano-molecular responses were further detected by Brady et al. ${ }^{69}$ on their tissue-engineered muscle 3D collagen construct adopting primary human skeletal muscle cells, masseter muscle biopsies. In 2008, Moon du et al..$^{70}$ described an in vitro preconditioning protocol that improved the contractility of engineered skeletal muscle after implantation 
in vivo. In their work, primary human muscle precursor cells (MPCs) were seeded onto collagen-based acellular tissue scaffolds and subjected to cyclic strain in a computer-controlled bioreactor system. Bioreactor preconditioning produced viable muscle tissue constructs with unidirectional orientation and contractile responses. This MPC-seeded constructs preconditioned in the bioreactor for 1 week were also implanted onto the latissimus dorsi muscle of athymic mice. Analysis of tissue constructs retrieved 1-4 weeks postimplantation showed that bioreactor-preconditioned constructs, but not statically cultured control tissues, generated tetanic and twitch contractile responses with a specific force of $1 \%$ and $10 \%$, respectively, of that observed on native latissimus dorsi.

Another kind of mechanical force, the pressure, was considered by Breuls et al. on their in vitro model system of engineered skeletal muscle tissue constructs. ${ }^{71}$ With this model system, the relationship between compressive tissue straining and cell damage initiation was investigated under well-defined environmental conditions. Compression of the engineered muscle tissue constructs revealed that cell death occurs within $1-2 \mathrm{~h}$ at clinically relevant straining percentages and that higher strains led to earlier damage initiation. In addition, the uniform distribution of dead cells throughout the constructs suggested that sustained deformation of the cells was the principal cause of cell death. For determining the tolerance of muscle cells to large mechanical strains, Gefen et al. ${ }^{72}$ used a new experimental method of determining the time-dependent critical compressive strains for necrotic cell death in a planar tissue-engineered construct under static loading. A half-spherical indentor was used to induce a nonuniform, concentric distribution of strains in the construct, and the data were calculated from the radius of the damage region in the construct versus time. The author regarded that was necessary for extrapolating biological damage from muscle-strain data in biomechanical studies of pressure ulcers and pressure-related deep tissue injury.

The key approach of developing a higher differentiated and more functional skeletal muscle tissue is electrical stimulation, which mimics the nerve stimulation during myogenesis, and during regeneration of injured skeletal muscle, further, electrically induced contractile activity promotes differentiation of myotubes. ${ }^{73}$ Chronic electrical stimulation of primary rat cells was shown to change the MHC expression with different impulse patterns. Moreover, MHC expression during myogenesis can be modulated in vitro by electrical stimulation in cell cultures that consist of predifferentiated skeletal muscle cells. ${ }^{74}$ Using electrical stimulation, Dennis et al. ${ }^{22,23}$ and Kosnik et al. ${ }^{67}$ analyzed their muscle tissue constructs, Myooids, which produced a peak twitch force of approximately $320 \mu \mathrm{N}$ and a tetanic force of approximately $575 \mu \mathrm{N}$ when stimulated electrically. Myooids also displayed many important functional similarities with adult skeletal muscle, including positive force frequency, and normal length-tension relationships. When the maximal twitch and tetanic forces were normalized to cross-sectional area, Myooids produced a specific force of $5-20 \mathrm{kN} / \mathrm{m}^{2}, 2-8 \%$ of typical adult values or $5-30 \%$ of newborn muscles. The contractility of Myooids was also similar to neonatal skeletal muscle with a time to peak tension of approximately $60 \mathrm{~ms}$ and a half relaxation time of 60-100 ms. Further, mechanical force and electrical stimulation were loaded on their rapidly generating 3D engineered muscles using fibrin gel casting at the same time. Three weeks after plating, the 3D engineered muscle generated a maximum twitch force of $329 \pm 26.3 \mu \mathrm{N}$ and a maximal tetanic force of $805.8 \pm 55 \mu \mathrm{N}$. The engineered muscles demonstrated normal physiological function, including length-tension and forcefrequency relationships. Treatment with insulin-like growth factor-I (IGF-I) resulted in a 50\% increase in force production, demonstrating that these muscles responded to hormonal interventions. ${ }^{25}$ In 2008, Serena et al. ${ }^{75}$ investigated the effect of exogenous electrical field, specifically designed to mimic part of the neuronal activity, on MPCs cultured within 3D collagen scaffolds. They showed that electric stimulation did not affect cell viability and increased by $65.6 \%$ the release rate of $\mathrm{NO}(\mathrm{x})$, an early molecular activator of satellite cells in vivo. $\mathrm{NO}(\mathrm{x})$ release rate was decreased by an inhibitor of NO synthase, both in stimulated and nonstimulated cultures, confirming the endocrine origin of the measured $\mathrm{NO}(\mathrm{x})$. Importantly, electrical stimulation also increased the expression of two myogenic markers, MyoD and Desmin. Their findings indicated that electrical stimulation could be a new strategy for the effective $3 \mathrm{D}$ expansion of MPCs in vitro without losing myogenic potential.

In addition, static magnetic field become a new interesting for those who attempt to engineer functional skeletal muscle. Coletti et al. ${ }^{76}$ indicated that static magnetic field can rescue of muscle differentiation and enhance parallel orientation of L6 myotubes of engineered muscle tissue. For overcoming the results of a uniform cell distribution only on the scaffold surface adopting conventional static techniques, Gefen et al. and Cimetta et al. ${ }^{77,78}$ invented a dynamic culture systems. They designed and developed a perfusion bioreactor able to ensure long-term culture conditions and uniform flow of medium through 3D CS. A mathematical model to assist the design of the experimental setup and of the operative conditions was developed. Their results proved that the dynamic culture conditions $(3.5 \mathrm{~mL} / \mathrm{min}$ flow rate) improved cell viability and lead to higher cell density and uniform distribution throughout the entire 3D CS for both C2C12 and satellite cells.

\section{Development of Other Skeletal Muscle Tissue Constructing}

Considering that innervation of in vitro generated muscle tissue constructs has to be addressed to provide functional muscle tissue in a clinical scenario, Bach et al. ${ }^{12,45,46}$ established a coculture system with neuronal slices of the spinal cord and myoblasts in a 3D fibrin matrix, and the results of their study confirmed that a 3D environment and neuronal tissue were required for the understanding of the control mechanisms that were essential for in vitro regenerating of highly differentiated skeletal muscle tissue. Meanwhile, a $3 \mathrm{D}$ nerve-muscle construct engineered by Larkin et al. ${ }^{79}$ displayed functional neuromuscular junctions and can be electrically stimulated to contract via the neural extensions projecting from the construct. Their immunohistochemical labeling indicated that the junctions between the nerve extensions and the muscle constructs contained clusters of acetylcholine receptors. Compared to muscles cultured without nerve explants, constructs formed from nerve-muscle coculture showed spontaneous contractions with an increase in frequency and force. Upon field stimulation, both twitch (twofold) and tetanus (1.7-fold) were greater in the nervemuscle coculture system. Contractions could be elicited 
by electrically stimulating the neural extensions, although smaller forces were produced than with field stimulation.

One of the major obstacles in engineering thick, complete tissues is the need to vascularize the tissue in vitro, which could maintain cell viability during tissue growth, induce structural organization, and promote vascularization upon implantation. Levenberg et al. ${ }^{80}$ induced endothelial vessel networks in engineered skeletal muscle tissue constructs using a 3D multiculture system consisting of myoblasts, embryonic fibroblasts, and endothelial cells coseeded on highly porous, biodegradable polymer scaffolds. Huang et al. ${ }^{24,25}$ self-organized 3D engineered muscle absenting of fibroblasts. Their results showed that addition of embryonic fibroblasts increased the levels of vascular endothelial growth factor expression in the construct and promoted formation and stabilization of the endothelial vessels. They also verified that prevascularization improved the vascularization, blood perfusion, and survival of the muscle tissue constructs after transplantation.

Myoblast transplantation is a potentially useful therapeutic tool in muscle diseases, and the seeking of an efficient micropatterned delivery system is developing. Boldrin et al. ${ }^{81}$ combined cell biology and polymer processing to create an appropriate microenvironment for in vivo transplantation of murine satellite cells. They prepared cells from single muscle fibers derived from C57BL/6-Tgn-enhanced green fluorescent protein transgenic mice and seeded within a special micropatterned PGA 3D scaffolds fabricated using soft lithography and thermal membrane lamination. They suggested that implantation of cellularized scaffolds was better than direct injection for delivering myogenic cells into regenerating skeletal muscle. In 2008, they further proved that, the micropatterned poly-lactic-glycolic acid 3D scaffolds seeded within primary human MPCs were able to participate in muscle regeneration, while scaffold-implanted muscles contained a greater number of human nuclei, as revealed by immunostaining and Western blot analyses, after implanting in predamaged tibialis anterior muscles of CD1 nude mice. ${ }^{82}$ Nevertheless, Beier et al. explored the injectable skeletal muscle. They injected expanded primary male myoblasts into muscle defects in female syngeneic rats using a two-way syringe (Duploject) within a 3D fibrin matrix. Detection and evaluation were performed using $\mathrm{Y}$ chromosome in situ hybridization, antidesmin immunostaining, and hematoxylin and eosin staining. This injectable skeletal tissue obtained well integration with host muscle fibers in a time-dependent manner in their research. ${ }^{83}$

Muscle tissue engineering provides a model for understanding the development of the myotendinous junction. The force exerted by a muscle must first be transmitted to the endomysium, perimysium, and epimysium and then to the tendon via the muscle-tendon interface or myotendinous junction. ${ }^{84}$ To produce a strong connection between the collagen fibers of the tendon and the actin filaments of the muscle tissue, the myotendinous junction develops through the deposition of a number of proteins that are important in creating a tight connection between the intracellular and ECM, such as laminin, integrin, vinculin, fibronectin, and talin. ${ }^{84}$ Swasdison and Mayne ${ }^{85}$ were the first to realize that the myotendinous junction could be modeled using engineered muscle. Modifying the cell-sheet technique pioneered by Vandenburgh ${ }^{17}$, they showed that the muscle fibers within their constructs formed attachments to the outer layer of collagen and showed extensive invaginations of the sarcolemma and surrounding basal lamina. Although the invaginations suggested that they were forming a myotendinous junction, direct insertions of the surrounding collagen fibers into the basal lamina of the muscle fibers were not observed. ${ }^{85}$ This issue had recently been explored more thoroughly using self-organizing engineered muscles to show that an immature myotendinous junction can be created in vitro. ${ }^{86}$ Larkin et al. ${ }^{86}$ used sections of adult, fetal, or engineered tendon in place of the sutures classically used as anchors in the self-organized model. Although the diameter, maximum isometric force, and specific force measurements of the constructs were not different with tendon anchors, when the constructs were subjected to physiological and above physiological levels of strain during strain-to-failure tests, the constructs failed in the muscle portion, thus retaining an intact muscle-tendon interface. Staining of the constructs for paxillin, a focal adhesion protein thought to be involved in mediating integrin adhesion at the myotendinous junction, showed its presence in all three muscletendon constructs. However, the expression of paxillin was more diffuse in the engineered muscle-tendon constructs than in the adult myotendinous junction, showing a pattern more similar to the neonatal myotendinous region. This suggested that the muscle-tendon constructs resembled an immature myotendinous junction and can be used as a tool to determine what was required for the development and maturation of this understudied interface.

\section{Patents Concerning with Skeletal Muscle Engineering}

For recently published patents concerning with skeletal muscle tissue engineering, most of them deal with different kinds of scaffolds and new matrix materials. In U.S. Patent 20070202189, ${ }^{87}$ Ahlfors provided methods for producing an acellular bioabsorbable structure that had biological regenerative properties (referred to hereafter as a "regeneration matrix"), which may be produced from any animal tissue, including muscle. Their invention provided methods of administering a regeneration matrix to a subject, wherein the regeneration matrix initiated and/or increased tissue regeneration. Damaged tissue, such as nerve, muscle, liver, heart, lung, and/or skin tissue, could be regenerated according to methods of the invention includes. Such a regeneration matrix may contain one or more of transferrin, serum albumin, serum albumin precursor, complement component 3, chains A-D hemoglobin, immunoglobulin $\mathrm{M}$, immunoglobulin G1, medullasin inhibitor 2, carbonic anhydrase, and/or cellulose acetate 1 protein, and the regeneration matrix was supplemented with one or more therapeutic agents such as proteins, peptides, drugs, cytokines, ECM molecules, and growth factors. This matrix can be seeded or mixed with cells, including myoblast or muscle progenitor cells. The main producing steps are isolating tissue sample, removing cells from the tissue sample to generate an acellular sample, and incubating the acellular sample in an incubation chamber for the formation of the acellular bioabsorbable tissue regeneration matrix. At the same time, Van dyke et al. (U.S. Patent 20070248638) ${ }^{88}$ provided another kind of bioscaffold from natural tissues by oxidizing a decellularized tissue to produce a bioscaffold having pores therein. The pore size and porosity were increased to better accommodate intact cells so that live 
cells can better infiltrate and inhabit the bioscaffold. The bioscaffold may be freeze-dried or lyophilized, sterilized, and (optionally) aseptically packaged for subsequent use. For those who attempted to reconstruct skeletal muscle tissue in vitro using acellular scaffolds, these patents were valuable references. The tissue material and matrix, mentioned in U.S. Patent 20060153797, ${ }^{89}$ was useful for promoting or facilitating growth, development, and differentiation of cells and tissues. More particularly, this invention provided a muscle-derived material comprising intact or extracted ECM and/or cells as well as cytokines, growth factors, and other components. The muscle preparations of the present invention resembled basement membrane and were derived from cellular-based material. This scaffold can be prepared and used in vitro or in vivo in muscle tissue engineering applications.

The ECM-based scaffolds retain the complex protein mixture present in the original ECM. Hence, these scaffolds retain functional cues necessary for organotypic differentiation of the target tissues. Further, these scaffolds, alone or in combination with other (synthetic) polymers, provide good mechanical properties, which facilitate cell penetration and proliferation within the scaffolds. Finally, the complex protein mix in these scaffolds contains also bioactive growth/ differentiation factors, which provide nutrition to support cell growth even without serum. Thus, inventors explored this field and have given some interesting products, such as in U.S. Patent 20080213389. ${ }^{90}$ Lelkes et al. created 3D fibrous and microporous scaffolds that retained the complexity of the ingredients and functionality of natural ECM. Electrospinning and/or lyophilization techniques were adopted in this invention. Both electrospun and lyophilized scaffolds were suitable for skeletal muscle tissue engineering purposes.

Turos et al. called his invention as biocomposite (U.S. Patent 20080124371), ${ }^{91}$ which includes a biotic material, such as collagen, and an abiotic material, such as ethylacrylatemethylmethacrylate copolymer, or poly(acrylate-styrene) copolymer. Various polymeric nanoparticles and ratios of polymer-to-biotic material (e.g., polymer-to-collagen) can be utilized to alter the mechanical properties of the biocomposite. In another patent (U.S. Patent 20040037813), ${ }^{92}$ the electroprocessed collagen compositions were taken as matrix material and, together with cells, can be used in tissue engineering field. Polymers such as poly lactic acid, PGA, copolymers of poly lactic acid and PGA, polycaprolactone, poly ethylene-co-vinyl acetate, poly vinyl acetate, polyethylene glycol, and poly ethylene oxide can be involved in these compositions. For tissue engineering scaffolds, the internal structure and the porosity will determine the functional effects of different constructing tissues. Manufacturing macroporous, biodegradable tissue engineering scaffolds with controlled pore interconnectivity and porosity is involved in U.S. Patent 20040026811. ${ }^{93}$ On the other hand, many novel scaffolds were used in muscle tissue engineering field and patented-for example, the cellulose acetate thin, porous membranes produced by electrospinning precursor polymer solutions in acetone (U.S. Patent 20070275458) ${ }^{94}$; muscle scaffolds included copolymers of a polyalkylene glycol and an aromatic polyester in the form of a matrix (U.S. Patent 20020072798 $)^{95}$; and compositions and methods for preparing electrospun matrices comprising at least one natural biological material component and at least one synthetic polymer material (U.S. Patent 20060204539). ${ }^{96}$ Associated with the egress and activity of seeded cells, a scaffold that was incorporated or was coated with a bioactive composition and regulated the egress of resident cells spatially and temporally was shown by Mooney et al. in their patent (U.S. Patent 20080044900). ${ }^{97}$ This device regulated egress through the physical or chemical characteristics of the scaffold itself. The permeability of the scaffold composition was regulated by selecting or engineering a material for greater or smaller pore size, density, polymer cross linking, stiffness, toughness, ductility, or viscoelasticity. The scaffold composition contained physical channels or paths through which cells can move more easily toward a targeted area of egress of the device or of a compartment within the device. The scaffold composition was optionally organized into compartments or layers, each with a different permeability, so that the time required for a cell to move through the device was precisely and predictably controlled. Migration was also regulated by the degradation, de- or rehydration, oxygenation, chemical or $\mathrm{pH}$ alteration, or ongoing self-assembly of the scaffold composition. These processes were driven by diffusion or cell secretion of enzymes or other reactive chemicals.

Making engineered muscle without a scaffold and using in implantation surgery were reported by Nakamura et al. in their recent patent (U.S. Patent 20080004713). ${ }^{98}$ The invention provided a synthetic tissue or complex that can be produced by culture and had a high level of differentiation ability. The present invention also provided a therapy for repairing and/or regenerating tissue using replacement and covering. By culturing cells under specific culture conditions such that medium contains an ECM synthesis promoting agent, the cells were organized and were easily detached from a culture dish. In addition, the self-contraction of the tissue can be regulated by culturing the tissue in a suspended manner. Therefore, it was possible to regulate the $3 \mathrm{D}$ shape of the tissue. Kosnik et al. developed this 3D connective tissue construct in their patent (U.S. Patent 20080199953) ${ }^{99}$ and used it extensively in skeletal muscle engineering field.

A critical procedure while engineering skeletal muscle is to generate multiple layers of skeletal muscle that are oriented in the same direction. The invention of Tresco et al. (U.S. Patent 20060140918 $)^{100}$ related to a bioartificial composite comprised of a substrate having at least one surface capable of the reception and growth promoting retention of a cellular preparation, and a first layer of adherent cells disposed on said surface. The first layer was prepared from the cellular preparation, and the cells comprising the first layer had cytoskeletal elements aligned uniformly, so that the bioartificial composite acted as a template to accept a second layer of cells upon the first layer. The device may be implanted for the promotion of muscle tissue regrowth. The 3D multilayer device serving as the template for cell adhesion and growth was also mentioned in Borenstein et al. patent (U.S. Patent 7371400). ${ }^{101}$ Yost et al. invented the aligned biopolymer scaffold for use in muscle tissue engineering and the other applications. Their invention was directed to a novel tubular tissue scaffold comprising a tube having a wall, wherein the wall included biopolymer fibrils that were aligned in a helical pattern around the longitudinal axis of the tube where the pitch of the helical pattern changed with the radial position in the tube wall. The scaffold was capable of directing the morphological pattern of attached and growing cells to form a helical pattern around the tube walls. ${ }^{102,103}$ 
During the development of the skeletal muscle engineering, the delicate construction devices, including different bioreactors, appear more simple and convenient to operate. The bioreactor of Hutmacher et al. comprised a chamber for containing cells or tissue cultures within a culture medium, a detector capable of detecting a change in one or more metabolites associated with growth of the cell or tissue cultures within the chamber, and a chamber drive capable of rotating the chamber at a first speed about a first axis and a second speed about a second axis, the second axis being disposed at an angle relative to the first axis. In use, the magnitudes of the first speed and the second speed were independently variable to each other (U.S. Patent 20060019388). ${ }^{104}$ Yoo et al.'s bioreactor was supplemented with a stretching and relaxing device, for enhancing the functionality of the muscle tissue formed on the bioreactor from the precursor muscle cells (U.S. Patent 20060239981). ${ }^{105}$ During 2003 and 2004, Bowlin et al. ${ }^{106,107}$ invented and published patents aiming exclusively at skeletal muscle tissue engineering. The production of them included an ECM, tendon, and muscle cells. The ECM was made of a matrix of electrospun polymer fibers. The tendon was made of extruded collagen fibers, and the muscle cells were disposed on the ECM in such a manner that the combination of components will functionally and structurally acted as normal muscle tissue. Vein's invention was prospective: they invented a nonhuman tissue-engineered meat product and a method for producing such meat product. The meat product comprised muscle cells that are grown ex vivo and was used for food consumption. The meat product may also comprise other cells such as fat cells or cartilage cells, or both, that were grown ex vivo together with the muscle cells (U.S. Patent 20050084958). ${ }^{108}$

\section{Future Perspectives and Conclusion}

Tissue engineering and regenerative medicine is an exiting interdisciplinary field that applies the principles of engineering and biology to the development of viable substitutes that restore the function of damaged tissues and organs. Skeletal muscle tissue engineering has developed rapidly over the last 20 years. With the development of simple and standardized machines in the next $2-3$ years, it will be possible for anyone to use tissue-engineered muscle to determine how exercise affects muscle physiology, turn on or off any gene and determine the resulting effect on muscle function quickly and inexpensively, provide an inexpensive screening process before more costly and time-consuming muscle-specific transgenic animals are created, screen inhibitor compounds to determine which molecular signaling pathways are required for muscle adaptation to exercise, and offer researchers a powerful tool to rapidly screen hundreds of genes/drugs for their ability to alter tissue function.

Growing new tissues (neoorganogenesis) is a complex process that requires the teamwork of developmental and cellular molecular biologists, engineers, material scientists, and physicians. As the techniques of tissue engineering become more sophisticated, the usefulness of these methods for supporting the possibilities of reconstructive surgery will hopefully become a reality. Future developments and the decision regarding which approach is more promising depend on the elucidation of the relationships among cell growth and differentiation, the 3D environment, the archi- tecture of the cells, and gene expression of the developmental process and the survival of the cells and integration in the host in in vivo experiments. As the techniques of tissue engineering become more sophisticated and as issues such as vascularization and innervation are addressed, the usefulness of these methods for reconstructive surgery may grow significantly.

\section{Disclosure Statement}

The work was supported in part by research grants from the National High-Tech Program of China (No. 2007AA022119), the Ministry of Education of China (No. 207082), and the National Natural Science Foundation of China (No. 30771045).

\section{References}

1. Mooney, D.J., and Mikos, A.G. Growing new organs. Sci Am 280, 60, 1999.

2. Bonassar, L.J., and Vacanti, C.A. Tissue engineering: the first decade and beyond. J Cell Biochem Suppl 30, 297, 1998.

3. Vangsness, C.T., Jr., Kurzweil, P.R., and Lieberman, J.R. Restoring articular cartilage in the knee. Am J Orthop 33, 29, 2004.

4. Oakes, B.W. Orthopaedic tissue engineering: from laboratory to the clinic. Med J Aust 180, S35, 2004.

5. Kopp, J., Jeschke, M.G., Bach, A.D., Kneser, U., and Horch, R.E. Applied tissue engineering in the closure of severe burns and chronic wounds using cultured human autologous keratinocytes in a natural fibrin matrix. Cell Tissue Bank 5, 81, 2004.

6. Kojima, K., Bonassar, L.J., Ignotz, R.A., Syed, K., Cortiella, J., and Vacanti, C.A. Comparison of tracheal and nasal chondrocytes for tissue engineering of the trachea. Ann Thorac Surg 76, 1884, 2003.

7. Chang, S.C., Tobias, G., Roy, A.K., Vacanti, C.A., and Bonassar, L.J. Tissue engineering of autologous cartilage for craniofacial reconstruction by injection molding. Plast Reconstr Surg 112, 793, 2003.

8. Horch, R.E., Debus, M., Wagner, G., and Stark, G.B. Cultured human keratinocytes on type I collagen membranes to reconstitute the epidermis. Tissue Eng 6, 53, 2000.

9. Law, P.K., Goodwin, T.G., Fang, Q., Deering, M.B., Duggirala, V., Larkin, C., Florendo, J.A., Kirby, D.S., Li, H.J., and Chen, M. Cell transplantation as an experimental treatment for Duchenne muscular dystrophy. Cell Transplant 2, 485, 1993.

10. Guettier-Sigrist, S., Coupin, G., Braun, S., Warter, J.M., and Poindron, $P$. Muscle could be the therapeutic target in SMA treatment. J Neurosci Res 53, 663, 1998.

11. Khodabukus, A., Paxton, J.Z., Donnelly, K., and Baar, K. Engineered muscle: a tool for studying muscle physiology and function. Exerc Sport Sci Rev 35, 186, 2007.

12. Bach, A.D., Stern-Straeterb, J., Beier, J.P., Bannasch, H., and Stark, G.B. Engineering of muscle tissue. Clin Plastic Surg 30, 589, 2003.

13. Bian, W., and Bursac, N. Tissue engineering of functional skeletal muscle: challenges and recent advances. IEEE Eng Med Biol Mag 27, 109, 2008.

14. Vandenburgh, H.H. Functional assessment and tissue design of skeletal muscle. Ann NY Acad Sci 961, 201, 2002.

15. Powell, C., Shansky, J., Del Tatto, M., Forman, D.E., Hennessey, J., Sullivan, K., Zielinski, B.A., and Vandenburgh, H.H. Tissue-engineered human bioartificial muscles 
expressing a foreign recombinant protein for gene therapy. Hum Gene Ther 10, 565, 1999.

16. Barr, E., and Leiden, J.M. Systemic delivery of recombinant proteins by genetically modified myoblasts. Science 254, 1507,1991

17. Vandenburgh, H.H., Karlisch, P., and Farr, L. Maintenance of highly contractile tissue-cultured avian skeletal myotubes in collagen gel. In Vitro Cell Dev Biol 24, 166, 1988.

18. Okano, T., and Matsuda, T. Hybrid muscular tissues: preparation of skeletal muscle cell-incorporated collagen gels. Cell Transplant 6, 109, 1997.

19. Shansky, J., Creswick, B., Lee, P., Wang, X., and Vandenburgh, $\mathrm{H}$. Paracrine release of insulin-like growth factor 1 from a bioengineered tissue stimulates skeletal muscle growth in vitro. Tissue Eng 12, 1833, 2006.

20. Cheema, U., Brown, R., Mudera, V., Yang, S.Y., McGrouther, G., and Goldspink, G. Mechanical signals and IGF-I gene splicing in vitro in relation to development of skeletal muscle. J Cell Physiol 202, 67, 2005.

21. Strohman, R.C., Bayne, E., Spector, D., Obinata, T., MicouEastwood, J., and Maniotis, A. Myogenesis and histogenesis of skeletal muscle on flexible membranes in vitro. In Vitro Cell Dev Biol 26, 201, 1990.

22. Dennis, R.G., and Kosnik, P.E. Excitability and isometric contractile properties of mammalian skeletal muscle constructs engineered in vitro. In Vitro Cell Dev Biol Anim 36, 327, 2000.

23. Dennis, R.G., Kosnik, P.E., Gilbert, M.E., and Faulkner, J.A. Excitability and contractility of skeletal muscle engineered from primary cultures and cell lines. Am J Physiol Cell Physiol 280, C288, 2001.

24. Huang, Y.C., Dennis, R.G., and Baar, K. Cultured slow vs. fast skeletal muscle cells differ in physiology and responsiveness to stimulation. Am J Physiol Cell Physiol 291, C11, 2006.

25. Huang, Y.C., Dennis, R.G., Larkin, L., and Baar, K. Rapid formation of functional muscle in vitro using fibrin gels. J Appl Physiol 98, 706, 2005.

26. Okano, T., Satoh, S., Oka, T., and Matsuda, T. Tissue engineering of skeletal muscle: highly dense, highly oriented hybrid muscular tissues biomimicking native tissues. ASAIO J 43, M749, 1997.

27. Okano, T., and Matsuda, T. Muscular tissue engineering: capillary-incorporated hybrid muscular tissues in vivo tissue culture. Cell Transplant 7, 435, 1998.

28. Saxena, A.K., Willital, G.H., and Vacanti, J.P. Vascularized three-dimensional skeletal muscle tissue-engineering. Biomed Mater Eng 11, 275, 2001.

29. Dusterhoft, S., and Pette, D. Satellite cells from slow rat muscle express slow myosin under appropriate culture conditions. Differentiation 53, 25, 1993.

30. Sutherland, R.S., Baskin, L.S., Hayward, S.W., and Cunha, G.R. Regeneration of bladder urothelium, smooth muscle, blood vessels and nerves into an acellular tissue matrix. J Urol 156, 571, 1996.

31. Parnigotto, P.P., Gamba, P.G., Conconi, M.T., and Midrio, P. Experimental defect in rabbit uretra repaired with acellular aortic matrix. Urol Res 28, 46, 2000.

32. Parnigotto, P.P., Marzaro, M., Artusi, T., Perrino, G., and Conconi, M.T. Short bowel syndrome: experimental approach to increase intestinal surface in rats by gastric homologous acellular matrix. J Pediatr Surg 35, 1304, 2000.

33. Borschel, G.H., Dennis, R.G., and Kuzon, W.J., Jr. Contractile skeletal muscle tissue-engineered on an acellular scaffold. Plast Reconstr Surg 113, 595; discussion 603-604, 2004.
34. Conconi, M.T., De Coppi, P., Bellini, S., Zara, G., Sabatti, M., Marzaro, M., Zanon, G.F., Gamba, P.G., Parnigotto, P.P., and Nussdorfer, G.G. Homologous muscle acellular matrix seeded with autologous myoblasts as a tissueengineering approach to abdominal wall-defect repair. Biomaterials 26, 2567, 2005.

35. De Coppi, P., Bellini, S., Conconi, M.T., Sabatti, M., Simonato, E., Gamba, P.G., Nussdorfer, G.G., and Parnigotto, P.P. Myoblast-acellular skeletal muscle matrix constructs guarantee a long-term repair of experimental full-thickness abdominal wall defects. Tissue Eng 12, 1929, 2006.

36. Adams, J.C., and Watt, F.M. Regulation of development and differentiation by the extracellular matrix. Development 117, 1183, 1993.

37. van Wachem, P.B., van Luyn, M.J., and da Costa, M.L. Myoblast seeding in a collagen matrix evaluated in vitro. J Biomed Mater Res 30, 353, 1996.

38. Freed, L.E., Vunjak-Novakovic, G., Biron, R.J., Eagles, D.B., Lesnoy, D.C., Barlow, S.K., and Langer, R. Biodegradable polymer scaffolds for tissue engineering. Biotechnology 12, 689, 1994.

39. Grande, D.A., Halberstadt, C., Naughton, G., Schwartz, R., and Manji, R. Evaluation of matrix scaffolds for tissue engineering of articular cartilage grafts. J Biomed Mater Res 34, 211, 1997.

40. Rebel, J.M., De Boer, W.I., Thijssen, C.D., Vermey, M., Zwarthoff, E.C., and Van der Kwast, T.H. An in vitro model of urothelial regeneration: effects of growth factors and extracellular matrix proteins. J Pathol 173, 283, 1994.

41. Ye, Q., Zund, G., Benedikt, P., Jockenhoevel, S., Hoerstrup, S.P., Sakyama, S., Hubbell, J.A., and Turina, M. Fibrin gel as a three dimensional matrix in cardiovascular tissue engineering. Eur J Cardiothorac Surg 17, 587, 2000.

42. Mikos, A.G., Sarakinos, G., Leite, S.M., Vacanti, J.P., and Langer, R. Laminated three-dimensional biodegradable foams for use in tissue engineering. Biomaterials 14, 323, 1993.

43. Juhasz, I., Murphy, G.F., Yan, H.C., Herlyn, M., and Albelda, S.M. Regulation of extracellular matrix proteins and integrin cell substratum adhesion receptors on epithelium during cutaneous human wound healing in vivo. Am J Pathol 143, 1458, 1993.

44. Bach, A.D., Bannasch, H., Galla, T.J., Bittner, K.M., and Stark, G.B. Fibrin glue as matrix for cultured autologous urothelial cells in urethral reconstruction. Tissue Eng 7, 45, 2001.

45. Bach, A.D., Galla, T.J., Schaefer, D., Bittner, K.M., and Stark, G.B. Tissue Engineering of Skeletal Muscle Using a 3-D-Muscle-Neuron Co-Culture System. Seattle: Plastic Surgery Research Council, 2000.

46. Bach, A.D., Beier, J., Bittner, K.M., and Stark, G.B. Muscle tissue engineering using fibrin as a matrix for a 3-d-muscleneuron co-culture system. Proceedings of the 2nd Biovalley Tissue Engineering Symposium. Cell Tissue Organ 164, 268, 1999.

47. Williamson, M.R., Adams, E.F., and Coombes, A.G. Gravity spun polycaprolactone fibres for soft tissue engineering: interaction with fibroblasts and myoblasts in cell culture. Biomaterials 27, 1019, 2006.

48. Masuko, T., Iwasaki, N., Yamane, S., Funakoshi, T., Majima, T., Minami, A., Ohsuga, N., Ohta, T., and Nishimura, S. Chitosan-RGDSGGC conjugate as a scaffold material for musculoskeletal tissue engineering. Biomaterials 26, 5339, 2005.

49. Shah, R., Sinanan, A.C., Knowles, J.C., Hunt, N.P., and Lewis, M.P. Craniofacial muscle engineering using a 
3-dimensional phosphate glass fibre construct. Biomaterials 26, 1497, 2005.

50. Huang, N.F., Patel, S., Thakar, R.G., Wu, J., Hsiao, B.S., Chu, B., Lee, R.J., and Li, S. Myotube assembly on nanofibrous and micropatterned polymers. Nano Lett 6, 537, 2006.

51. Riboldi, S.A., Sampaolesi, M., Neuenschwander, P., Cossu, G., and Mantero, S. Electrospun degradable polyesterurethane membranes: potential scaffolds for skeletal muscle tissue engineering. Biomaterials 26, 4606, 2005.

52. Lam, M.T., Sim, S., Zhu, X., and Takayama, S. The effect of continuous wavy micropatterns on silicone substrates on the alignment of skeletal muscle myoblasts and myotubes. Biomaterials 27, 4340, 2006.

53. Boontheekul, T., and Mooney, D.J. Regulating myoblast phenotype through controlled alginate scaffold degradation: a delivery vehicle for skeletal muscle tissue engineering. Eur Cells Mater 7 Suppl 2, 14, 2004.

54. Huber, A., Pickett, A., and Shakesheff, K.M. Reconstruction of spatially orientated myotubes in vitro using electrospun, parallel microfibre arrays. Eur Cell Mater 14, 56, 2007.

55. Yan, W., George, S., Fotadar, U., Tyhovych, N., Kamer, A., Yost, M.J., Price, R.L., Haggart, C.R., Holmes, J.W., and Terracio, L. Tissue engineering of skeletal muscle. Tissue Eng 13, 2781, 2007.

56. Vandenburgh, H., Shansky, J., Benesch-Lee, F., Barbata, V., Reid, J., Thorrez, L., Valentini, R., and Crawford, G. Drugscreening platform based on the contractility of tissueengineered muscle. Muscle Nerve 37, 438, 2008.

57. Choi, J.S., Lee, S.J., Christ, G.J., Atala, A., and Yoo, J.J. The influence of electrospun aligned poly(epsilon-caprolactone)/ collagen nanofiber meshes on the formation of self-aligned skeletal muscle myotubes. Biomaterials 29, 2899, 2008.

58. Kroehne, V., Heschel, I., Schügner, F., Lasrich, D., Bartsch, J.W., and Jockusch, H. Use of a novel collagen matrix with oriented pore structure for muscle cell differentiation in cell culture and in grafts. J Cell Mol Med 12, 1640, 2008.

59. Propst, J.T., Fann, S.A., Franchini, J.L., Hansen, K.J., Yost, M.J., Lessner, S.M., and Terracio, L. Focused in vivo genetic analysis of implanted engineered myofascial constructs. J Investig Surg 22, 35, 2009.

60. Goldspink, D.F., Cox, V.M., Smith, S.K., Eaves, L.A., Osbaldeston, N.J., Lee, D.M., and Mantle, D. Muscle growth in response to mechanical stimuli. Am J Physiol 268, E288, 1995.

61. Goldspink, D.F., Easton, J., Winterburn, S.K., Williams, P.E., and Goldspink, G.E. The role of passive stretch and repetitive electrical stimulation in preventing skeletal muscle atrophy while reprogramming gene expression to improve fatigue resistance. J Card Surg 6 Suppl, 218, 1991.

62. Powell, C.A., Smiley, B.L., Mills, J., and Vandenburgh, H.H. Mechanical stimulation improves tissue-engineered human skeletal muscle. Am J Physiol Cell Physiol 283, C1557, 2002.

63. Vandenburgh, H.H. Dynamic mechanical orientation of skeletal myofibers in vitro. Dev Biol 93, 438, 1982.

64. Vandenburgh, H., and Kaufman, S. In vitro model for stretch-induced hypertrophy of skeletal muscle. Science 203, 265, 1979.

65. Baar, K., Torgan, C.E., Kraus, W.E., and Esser, K. Autocrine phosphorylation of p70(S6k) in response to acute stretch in myotubes. Mol Cell Biol Res Commun 4, 76, 2000.

66. Matsumoto, T., Sasaki, J., Alsberg, E., Egusa, H., Yatani, H., and Sohmura, T. Three-dimensional cell and tissue patterning in a strained fibrin gel system. PLoS ONE 2, e1211, 2007.
67. Kosnik, P.E., Faulkner, J.A., and Dennis, R.G. Functional development of engineered skeletal muscle from adult and neonatal rats. Tissue Eng 7, 573, 2001.

68. Vandenburgh, H.H., Swasdison, S., and Karlisch, P. Computer-aided mechanogenesis of skeletal muscle organs from single cells in vitro. FASEB J 5, 2860, 1991.

69. Brady, M., Brown, R., Lewis, M., and Mudera, V. Mechanical behaviour of primary human skeletal muscle cells and isolated on-myogenic cells within a 3D construct. Eur Cells Mater 10 Suppl 2, 29, 2005.

70. Moon du, G., Christ, G., Stitzel, J.D., Atala, A., and Yoo, J.J. Cyclic mechanical preconditioning improves engineered muscle contraction. Tissue Eng Part A 14, 473, 2008.

71. Breuls, R.G., Bouten, C.V., Oomens, C.W., Bader, D.L., and Baaijens, F.P. Compression induced cell damage in engineered muscle tissue: an in vitro model to study pressure ulcer aetiology. Ann Biomed Eng 31, 1357, 2003.

72. Gefen, A., van Nierop, B., Bader, D.L., and Oomens, C.W. Strain-time cell-death threshold for skeletal muscle in a tissue-engineered model system for deep tissue injury. J Biomech 41, 2003, 2008.

73. Dusterhoft, S., and Pette, D. Effects of electrically induced contractile activity on cultured embryonic chick breast muscle cells. Differentiation 44, 178, 1990.

74. Naumann, K., and Pette, D. Effects of chronic stimulation with different impulse patterns on the expression of myosin isoforms in rat myotube cultures. Differentiation 55, 203, 1994.

75. Serena, E., Flaibani, M., Carnio, S., Boldrin, L., Vitiello, L., De Coppi, P., and Elvassore, N. Electrophysiologic stimulation improves myogenic potential of muscle precursor cells grown in a 3D collagen scaffold. Neurol Res 30, 207, 2008.

76. Coletti, D., Teodori, L., Albertini, M.C., Rocchi, M., Pristerà, A., Fini, M., Molinaro, M., and Adamo, S. Static magnetic fields enhance skeletal muscle differentiation in vitro by improving myoblast alignment. Cytometry A 71, 846, 2007.

77. Gefen, A., Cornelissen, L.H., Gawlitta, D., Bader, D.L., and Oomens, C.W. The free diffusion of macromolecules in tissue-engineered skeletal muscle subjected to large compression strains. J Biomech 41, 845, 2008.

78. Cimetta, E., Flaibani, M., Mella, M., Serena, E.., Boldrin, L., De Coppi, P., and Elvassore, N. Enhancement of viability of muscle precursor cells on 3D scaffold in a perfusion bioreactor. Int J Artif Organs 30, 415, 2007.

79. Larkin, L.M., Van der Meulen, J.H., Dennis, R.G., and Kennedy, J.B. Functional evaluation of nerve-skeletal muscle constructs engineered in vitro. In Vitro Cell Dev Biol Anim 42, 75, 2006.

80. Levenberg, S., Rouwkema, J., Macdonald, M., Garfein, E.S., Kohane, D.S., Darland, D.C., Marini, R., van Blitterswijk, C.A., Mulligan, R.C., D'Amore, P.A., and Langer, R. Engineering vascularized skeletal muscle tissue. Nat Biotechnol 23, 879, 2005.

81. Boldrin, L., Elvassore, N., Malerba, A., Flaibani, M., Cimetta, E., Piccoli, M., Baroni, M.D., Gazzola, M.V., Messina, C., Gamba, P., Vitiello, L., and De Coppi, P. Satellite cells delivered by micro-patterned scaffolds: a new strategy for cell transplantation in muscle diseases. Tissue Eng 13, 253, 2007.

82. Boldrin, L., Malerba, A., Vitiello, L., Cimetta, E., Piccoli, M., Messina, C., Gamba, P.G., Elvassore, N., and De Coppi, P. Efficient delivery of human single fiber-derived muscle precursor cells via biocompatible scaffold. Cell Transplant 17, 577, 2008.

83. Beier, J.P., Stern-Straeter, J., Foerster, V.T., Kneser, U., Stark, G.B., and Bach, A.D. Tissue engineering of injectable muscle: 
three-dimensional myoblast-fibrin injection in the syngeneic rat animal model. Plast Reconstr Surg 118, 1113, 2006.

84. Edom-Vovard, F., and Duprez, D. Signals regulating tendon formation during chick embryonic development. Dev Dyn 229, 449, 2004.

85. Swasdison, S., and Mayne, R. In vitro attachment of skeletal muscle fibers to a collagen gel duplicates the structure of the myotendinous junction. Exp Cell Res 193, 227, 1991.

86. Larkin, L.M., Calve, S., Kostrominova, T.Y., and Arruda, E.M. Structure and functional evaluation of tendon-skeletal muscle constructs engineered in vitro. Tissue Eng 12, 3149, 2006.

87. Ahlfors, J.-e (Westborough, MA). United States Patent 20070202189. Acellular bioabsorbable tissue regeneration matrices.

88. Van dyke, M.E. (Winston-Salem, NC), Christ, G.J. (Lewisville, NC), and Whitlock, P.W (Winston-Salem, NC). United States Patent 20070248638. Structurally modified acellular tissue engineering scaffolds and methods of production.

89. Bortolotto, S.K. (Nunawading, Australia), Messina, A. (Eltham, Australia), and Abberton, K.M (Glen Waverley, Australia). United States Patent 20060153797. Tissue material and matrix.

90. Lelkes, P.I. (Cherry Hill, NJ), Li, M. (Philadelphia, PA), Perets, A. (Narbeth, PA), Poblete, H. (Philadelphia, PA), and Lazarovici, P (Jerusalem, IL). United States Patent 20080213389. Three-dimensional scaffolds for tissue engineering made by processing complex extracts of natural extracellular matrices.

91. Turos, E. (Wesley Chapel, FL), Koob, T.J. (Tampa, FL), and Greenhalgh, K.R (Tampa, FL). United States Patent 20080124371. Biocomposite for artificial tissue design.

92. Simpson, D.G. (Mechanicsville, VA), Bowlin, G.L. (Mechanicsville, VA), Wnek, G.E. (Midlothian, VA), Stevens, P.J. (Richland Hills, TX), Carr, M.E. (Midlothian, VA), Matthews, J.A. (Glen Allen, VA), and Rajendran, S (East Haven, CT). United States Patent 20040037813. Electroprocessed collagen and tissue engineering.

93. Murphy, W.L. (Chicago, IL), Dennis, R.G. (Ann Arbor, MI), and Mooney, D.J (Dexter, MI). United States Patent 20040026811. Tissue engineering scaffolds.

94. Gouma, P.-i (Port Jefferson, NY). United States Patent 20070275458. Three dimensional-BIO-mimicking active scaffolds.

95. Riesle, J.U. (Amsterdam, The Netherlands), Van, B., Clemens A. (Hekendorp, The Netherlands), Papadaki, M. (Cambridge, MA), and Langer, R (Newton, MA). United States Patent 20020072798. Muscle tissue engineering.

96. Atala, A. (Winston-Salem, NC), Yoo, J. (Winston-Salem, NC), Lim, G. (Winston-Salem, NC), Czerw, R. (Clemmons, NC), Soker, S. (Greensboro, NC), and Stitzel, J (WinstonSalem, NC). United States Patent 20060204539. Electrospun cell matrices.

97. Mooney, D.J. (Sudbury, MA), Ali, O.A.-r. (Bloomington, $\mathrm{MN}$ ), Barros, S.E.A.E. (Somerville, MA), Kong, H.J. (Cambridge, MA), Hill, E.E., Jr. (Ypsilanti, MI), and Boontheekul, T (Bangkok, Thailand). United States Patent 20080044900. Scaffolds for cell transplantation.

98. Nakamura, N. (Nishinomiya-shi, Japan), Yoshikawa, H. (Toyonaka-shi, Japan), and Ando, W (Ibaraki-shi, Japan). United States Patent 20080004713. Scaffold-free selforganized 3d synthetic tissue.

99. Kosnik, P.E. (Bay City, MI), Dennis, R.G. (Ann Arbor, MI), Calve, S.C. (Darien, CT), and Arruda, E.M (Ann Arbor, MI).
United States Patent 20080199953. System and method for forming a connective tissue construct.

100. Tresco, P.A. (Sandy, UT), Biran, R. (Holladay, UT), and Noble, M.D (Brighton, NY). United States Patent 20060140918. Bioartificial device for propagation of tissue, preparation and uses thereof.

101. Borenstein, J.T. (Cambridge, MA), King, K.R. (Cambridge, MA), Terai, H. (Osaka, Japan), and Vacanti, J.P (Boston, MA). United States Patent 7371400. Multilayer device for tissue engineering.

102. Yost, M.J. (Lexington, SC), Gore, M.C. (West Columbia, SC), Terracio, L. (New York, NY), Goodwin, R.L. (Columbia, SC), and Goldsmith, E.C (Lexington, SC). United States Patent 7338517. Tissue scaffold having aligned fibrils and artificial tissue comprising the same.

103. Yost, M.J. (Lexington, SC), Gore, M.C. (West Columbia, SC), Terracio, L. (New York, NY), Goodwin, R.L. (Columbia, SC), and Goldsmith, E.C (Lexington, SC). United States Patent 20080147199. Tissue scaffold having aligned fibrils, apparatus and method for producing the same, and artificial tissue and methods of use thereof.

104. Hutmacher, D.W. (Sunset Lodge, Singapore), Teoh, S.H. (Singapore, Singapore), Ranawake, M. (Hurstville, Australia), Chong, W.S. (Singapore, Singapore), Ting, K.S. (Singapore, Singapore), Chua, K.C. (Singapore, Singapore), Myint, T. (Singapore, Singapore), Puah, C.M. (Singapore, Singapore), Foo, T.T. (Singapore, Singapore), and Schantz, J.-t (Singapore, Singapore). United States Patent 20060019388. Bioreactor for growing cell or tissue cultures.

105. Yoo, J. (Winston-Salem, NC), Stitzel, J. (Winston-Salem, NC), Atala, A. (Winston-Salem, NC), and Christ, G (Winston-Salem, NC). United States Patent 20060239981. Bioreactor system and method of enhancing functionality of muscle cultured in vitro.

106. Bowlin, G.L. (Mechanicsville, VA), Wnek, G. (Midlothian, VA), Simpson, D.G. (Mechanicsville, VA), and Terracio, L (Columbia, SC). United States Patent 6592623. Engineered muscle.

107. Bowlin, G.L. (Mechanicsville, VA), Wnek, G. (Midlothian, VA), and Simpson, D.G (Mechanicsville, VA). United States Patent 20040009600. Engineered muscle.

108. Vein, J (Los Angeles, CA). United States Patent 2005008 4958. Tissue engineered meat for consumption and a method for producing tissue engineered meat for consumption.

Address correspondence to: Guang-Qian Zhou, Ph.D.

Department of Orthopaedics and Traumatology The University of Hong Kong

Li Ka Shine Faculty of Medicine

21 Sassoon Road

Hong Kong

P.R. China

Division of Tissue Engineering and Stem Cells Key State Laboratory of Biotherapy Sichuan University Chengdu, Sichuan P.R. China

E-mail: gqzhou@hkucc.hku.hk

Received: February 9, 2009 Accepted: May 21, 2009

Online Publication Date: July 6, 2009 
